\title{
Biblioteconomia e ciência da informação e os limites da interdisciplinaridade: fomentando práticas profissionais
}

Jorge Santa anna

Resumo: Objetiva discutir aspectos relacionais entre a Ciência da Informação e a Biblioteconomia, delineando os limites de atuação e abrangência de cada uma, com vistas a demonstrar o caráter interdisciplinar e sistêmico abrangido por ambas as áreas. Através de revisão bibliográfica em coletâneas e artigos brasileiros sobre o assunto, busca-se determinar evidências que confirmam a ampliação do mercado de trabalho dos profissionais da informação, enfatizando a contribuição das novas tecnologias e da sociedade da informação no desenvolvimento acentuado dessas áreas do saber. Conclui que as duas áreas são afins e complementares, mas cada uma com seu escopo de atuação científica e profissional, sendo que, a tendência interdisciplinar favorece a ampliação das práticas profissionais, estabelecendo novas pesquisas e competências profissionais, integrando um ciclo ininterrupto e fortemente instituído.

Palavras-chave: Ciência da Informação. Biblioteconomia. Profissional da Informação. Novas tecnologias. Documentação. Interdisciplinaridade.

\section{INTRODUÇÃO}

A Ciência da Informação é um campo científico em formação, instituída no Brasil a partir de meados do século XX e aceita como uma área interdisciplinar a muitos outros campos do saber. Por apresentar a informação como seu principal objeto de trabalho/estudo (LE COADIC, 2004), evidencia-se que, na sociedade atual, sustentada na informação, essa área do saber humano representa a chave que abre as portas para o conhecimento.

A partir do aparecimento dessa ciência no Brasil, inúmeros estudos são realizados com vistas a delimitar seus limites de atuação (GUIMARÃES, 1997; MULLER, 2000; SMIT, 2000; VALENTIM, 2000; ORTEGA, 2004; OLIVEIRA, 2005; SIQUEIRA, 2010; ARAÚJO, 2013; ARAÚJO, 2014a, ARAÚJO, 2014b, dentre outros), 
a ponto de não abranger outros campos a ele similares, objetivando regulamentar a profissão, com corpo teórico consolidado e prática profissional reconhecida e necessária às resoluções de problemas da sociedade.

Nessa tentativa, inúmeras dificuldades vieram à tona, uma vez que a Ciência da Informação constitui uma área ampla, que envolve todas as etapas do ciclo da informação, desde sua geração, processamento, armazenamento e uso dessa informação (LE COADIC, 2004). Analisando todas as etapas do ciclo da informação, constata-se a presença de muitas outras profissões que abrangem algumas etapas do ciclo, como a Biblioteconomia, a Arquivologia, a Documentação, o Jornalismo, dentre outras.

Diante dessa dificuldade em instituir a Ciência da Informação como uma única área no gerenciamento total da informação, essa ciência foi caracterizada como uma grande área formada por outras áreas. Assim, inúmeros estudos tentam determinar quais áreas são abrangidas, sendo que a Museologia, a Biblioteconomia e a Arquivologia mais se destacam, consideradas como as "Três Marias" (SMIT, 2000).

Especificamente, no ano 2004, a Classificação Brasileira de Ocupações (CBO) (2003) reconhece como profissionais da informação apenas os bibliotecários. A partir de então, constata-se a presença marcante e interdisciplinar entre essas duas áreas, consideradas como complementares e includentes. Pode-se, a senso de humor, determinar essas ciências como "irmãs gêmeas".

Todavia, o corpo teórico da Ciência da Informação se formou a partir do novo conceito de documento atribuído aos suportes informacionais, evidenciado com a renovação constante da tecnologia. O conceito amplo de documento, trazido pela Documentação, foi um dos fatores que tornou essa ciência com caráter genérico. Outro fator que tem contribuído para ampliar o escopo de atuação da Ciência da Informação foi a evolução da Recuperação da Informação, intensificada, sobremaneira, com o advento das novas tecnologias da informação (OLIVEIRA, 2005).

A Biblioteconomia possui um maior histórico de formação e desenvolvimento no Brasil, além de ser uma área clássica reconhecida mundialmente, por isso, muito se questiona a possibilidade de transformá-la na própria Ciência da Informação. Esse fato não é possível devido ao aspecto complexo dos mecanismos de busca e recuperação da 
informação, que requerem conhecimentos de ciências cognitivas, comunicativas e sociais, o que não é preocupação primordial da Biblioteconomia (OLIVEIRA, 2005).

Sendo assim, o objetivo deste artigo é discutir aspectos relacionais entre a Ciência da Informação e a Biblioteconomia, delineando os limites de atuação e abrangência de cada uma, com vistas a demonstrar o caráter interdisciplinar e sistêmico abrangido por ambas as áreas.

A fim de se atingir esse objetivo, a metodologia utilizada foi a pesquisa bibliográfica em coletâneas de Biblioteconomia e Ciência da Informação existentes na literatura brasileira, além da consulta a artigos publicados em periódicos científicos da área de Biblioteconomia e Ciência da Informação. O estudo foi sustentado, de modo geral, por autores renomados da área, sendo utilizadas as seguintes coletâneas: "Profissionais da informação: formação, perfil e atuação profissional”, coletânea organizada por Marta Lígia Pomim Valentim (2000); "Ciência da Informação e Biblioteconomia: novos conteúdos e espaços de atuação" de Marlene de Oliveira (2005); "Profissional da informação: o espaço de trabalho", de Sofia Galvão Baptista e Suzana Pinheiro Machado Mueller (2004); "Formação do profissional da informação" e "Atuação profissional na área de informação", ambas organizadas por Marta Lígia Pomim Valentim, a primeira no ano de 2002 e a segunda em 2004. No que se refere aos artigos, destacam-se como principais a publicação de Ortega (2004), Siqueira (2010), Araújo (2013), Araújo (2014a), Araújo (2014b), dentre outros.

Embora existam opiniões divergentes no que se refere às origens da Ciência da Informação, assim como seus relacionamentos com a Biblioteconomia, neste estudo abordam-se três principais fatores, os quais exercem maior interferência na consolidação das duas áreas, que são: o aspecto interdisciplinar de ambas as áreas, o desenvolvimento da Documentação e a questão da Recuperação da Informação, assim como apontam os estudos de Ortega (2004), Oliveira (2005) e Araújo (2014a, 2014b), dentre outros.

O estudo foi estruturado com base na reflexão dos seguintes assuntos: as relações entre Biblioteconomia e Ciência da Informação, a questão da Documentação e aspectos sobre a Recuperação da Informação, abordando teorias e discussões de diferentes autores 
brasileiros que, em linhas gerais, dividem as mesmas opiniões a respeito do nascimento e formação da Ciência da Informação e suas interdisciplinaridades.

\section{CIÊNCIA DA INFORMAÇÃO E BIBLIOTECONOMIA: OS LIMITES INTERDISCIPLINARES}

A Ciência da Informação e a Biblioteconomia condicionam seus fazeres em meio ao emaranhado de informações que permeiam as sociedades. A revolução tecnológica proporcionou a criação de diferentes suportes a fim de armazenar a informação gerada, sendo que as técnicas de gerenciamento informacional devem atender as diferentes mídias existentes, desde os suportes tradicionais (impressos) aos suportes disponibilizados em meio digital.

No entanto, mesmo possuindo o mesmo objeto de trabalho (a informação), bem como possuírem muitos pontos em comum, especialmente, no que se refere à organização e disseminação da informação em quaisquer suportes e ambientes, as duas ciências se sustentam em paradigmas diferentes (OLIVEIRA, 2005).

Enquanto a Biblioteconomia se afirma no paradigma da biblioteca, considerada como instituição social, a Ciência da Informação delimita-se a processos mais complexos e amplos, notadamente no que diz respeito à recuperação, disseminação e uso da informação. Segundo Oliveira (2005, p. 23), esse paradigma compõe-se "[...] de um grupo de ideias relativas ao processo que envolve o movimento da informação em um sistema de comunicação humana [...]".

Considera-se, portanto, que a Ciência da Informação contempla preocupações que extrapolam o tratamento aferido aos documentos, através de técnicas e metodologias biblioteconômicas, pois essas atividades são contempladas pela Biblioteconomia (ORTEGA, 2004). A Ciência da Informação, segundo Borko (1968), constitui uma disciplina científica ampla, cuja missão é analisar as propriedades, características e o comportamento da informação, considerando, também, as forças que interferem na 
dinamicidade do fluxo informacional. Assim, essa ciência não se adentra, tão somente, ao tratamento documentário, mas se preocupa em entender como a informação é acessada e utilizada.

No intuito de garantir o acesso à informação, bem como entender as forças que impulsionam a formação e tramitação da informação, a Ciência da Informação investiga as tecnologias que viabilizam o acesso, assim como analisa, também, questões comportamentais e cognitivas, tendo em vista, conhecer o usuário da informação e como ele processa a informação de modo a agregar-lhe valor (BORKO, 1968). Nesse aspecto, esse campo do saber está relacionado "[...] ao corpo de conhecimentos relativos à origem, coleta, organização, estocagem, recuperação, interpretação, transmissão, transformação e uso de informação [...]” (BORKO, 1968, p. 3, grifo nosso).

Convém mencionar que a própria historiografia da Biblioteconomia revela o seu caráter técnico e operacional realizado junto aos suportes de informação, tendo como objetivo primordial, ao longo dos séculos, permitir a organização do conhecimento registrado. A trajetória evolutiva da biblioteca revela o aperfeiçoamento dos instrumentos de representação e organização de documentos que, juntamente com a Bibliografia e Documentação demonstra a importância da Biblioteconomia e sua relação com outras disciplinas no processo de tratamento e organização de acervos (ORTEGA, 2004).

Assim, percebe-se que a Biblioteconomia, por apresentar um longo período de existência, sempre esteve, em toda sua trajetória histórica, atrelada ao suporte de informação, ou seja, as atividades cabíveis ao bibliotecário era a de gerir esse suporte, através de técnicas específicas, seja catalogando, indexando e/ou classificando todos os itens que eram gerados pela sociedade. Nesse contexto, a Biblioteconomia se apresenta como ciência em prol dos suportes informacionais e seu tratamento (ARAÚJO; OLIVEIRA, 2005). Nesse enfoque, recorre-se às palavras de Saracevic (1996, p. 46) quanto declara que "[...] A biblioteconomia tem uma longa e orgulhosa história, remontando a três mil anos, devotada à organização, à preservação e ao uso dos registros gráficos humanos".

Nos dias atuais, nota-se que, a Sociedade da Informação, por meio do avanço tecnológico, vem proporcionando à Biblioteconomia uma nova postura de trabalho: além 
de servirem como depositárias da informação (função de custódia), as bibliotecas aprimoram seus serviços viabilizando o acesso à informação sem considerar as limitações de tempo e de espaço (ARAÚJO; OLIVEIRA, 2005).

Em linhas gerais, a atuação do profissional, ao longo dos tempos, se fez em duas dimensões: a técnica e a humanista. A primeira refere-se às tarefas técnicas de organização da informação, já na segunda, as atividades desse profissional estão "[...] voltadas para a cultura, para a educação, para o saber, para o conhecimento, tendo características que permitiam incluí-los como segmentos direcionados para atender necessidades no âmbito do espírito do homem" (ALMEIDA JÚNIOR, 2000, p. 45).

No contexto da explosão tecnológica, o novo espaço de trabalho caminha para o ambiente digital. Desse modo, a internet, por exemplo, de acordo com Baptista (2004), tende a se tornar um espaço para a atuação do bibliotecário. A oportunidade de trabalho é gerada pelo excesso e desorganização da informação, que requer um bibliotecário para filtrá-la e organizá-la.

Ao gerenciar o fluxo informacional, o bibliotecário realiza todos os processos de trabalho, necessários à posse informacional por parte do usuário, no entanto, os inúmeros mecanismos de busca, de disseminação e de uso por parte dos usuários permanecem ausentes dos fazeres biblioteconômicos.

Esse avanço da Biblioteconomia nas últimas décadas demonstra sua interligação acentuada à Ciência da Informação, pois muitos problemas inerentes aos fluxos de informação, ao comportamento do usuário, aos novos métodos para formulação de armazenamento e dinamização de documentos eletrônicos, são alguns desafios que cabem à Ciência da Informação propor soluções no intuito de contribuir com a prática bibliotecária (ARAÚJO, 2014a).

Saracevic (1996) comenta em sua tese que a Ciência da Informação inova por trabalhar questões mais complexas, não se adentrando, tão somente, a fazeres técnicos, assim como não se limitando apenas às tecnologias, pois, segundo o autor, deve-se considerar nesses novos tempos o humano como fator primordial para o efetivo uso dos recursos tecnológicos.

Na visão desse autor, a Ciência da Informação preocupa-se com problemas 
advindos do desenvolvimento tecnológico e que não foram superados pelas áreas do conhecimento até então existentes. Portanto,

Nas últimas quatro décadas a CI apresentou contribuições que influenciaram o modo como a informação é manipulada na sociedade e pela tecnologia e também permitiu melhor compreensão para um rol de problemas, processos e estruturas associados ao conhecimento, à informação e ao comportamento humano frente à informação. A CI desenvolveu um corpo organizado de conhecimentos e competências profissionais ligados às questões informacionais. Os fatos demonstram a veracidade dessas conclusões (SARACEVIC, 1996, p. 60).

Percebe-se o aspecto humano como uma das bases que edifica a Ciência da Informação, não que essa seja a única, mas apenas uma das muitas características dessa ciência. Araújo (2014b) discorre que a Ciência da Informação é uma ciência pósmoderna, humana e social, que se desenvolveu a partir da ampliação do conceito de informação, que, desvinculando-se da ideia de documento, fez brotar novos e amplos questionamentos. A informação passou a ser vista em diferentes vertentes, qual seja: informação como mensagem, informação relacionada ao processamento cognitivo e compreensão, e, o terceiro aspecto, a informação como elemento agregado a um contexto.

Com efeito, a Ciência da Informação tem se manifestado como uma ciência ampla que envolve outras áreas, em uma relação de reciprocidade, dada a complexidade dos fenômenos sociais e informacionais da pós-modernidade. No entendimento de Araújo (2014b), a história da Ciência da Informação tem sido, pois, a história da diversidade, tornando a área um espaço da convivência do diverso, o que tem proporcionado à Ciência da Informação um campo “[...] com muita criatividade para a formulação de novos conceitos, muita agilidade para a compreensão de novos fenômenos e o desenho de novos âmbitos de pesquisa, além de fôlego para dialogar com as mais distintas áreas disciplinares [...]" (ARAÚJO, 2014b). 
Não resta dúvida de que a Ciência da Informação e a Biblioteconomia se entrecruzam, possuindo práticas, objetivos e problemas semelhantes. No entanto, é importante considerar que cada área possui seu escopo de atuação, sendo sustentado por princípios diferentes e que garantam para a delimitação de campos complementares, porém, adversos. Nesse enfoque, os profissionais dessas áreas, ao se encontrarem, são regidos por uma sinergia que proporciona o avanço do conhecimento e consumação de melhorias para ambos os campos (ASIST, 2005).

Para Winter (1996 ${ }^{1}$ apud NEVES; CRUZ, 2000), é importante considerar que a interdisciplinaridade existente entre as diversas áreas do conhecimento é oriunda das características semelhantes entre uma área e outra. No entanto, mesmo havendo pontos de convergências, existem princípios delimitadores que sustentam ou concebem de forma diferente cada área. Portanto, as disciplinas, em geral, são constituídas por grupos de pessoas que têm metas intelectuais comuns, sendo, como qualquer grupo social, subculturas que frequentemente são incompreensíveis ou impenetráveis para não iniciados.

Entende-se que a interdisciplinaridade constitui o auxílio mútuo que uma área proporciona a outra, em virtude das semelhanças que apresentam, e é através dessa relação que nascem novos fazeres, novas práticas, por conseguinte, esse fato desencadeia o crescimento do saber inerente a uma determinada área de conhecimento (NEVES; CRUZ, 2000).

Logo, a Ciência da Informação é uma ciência extremamente interdisciplinar por natureza (SARACEVIC, 1996), como também, pode-se dizer que além de interdisciplinar ela é transdisciplinar, uma vez que seu objeto de pesquisa, a informação, está presente em todos os campos do saber, o que lhe afere um caráter mais abrangente e integrado (ARAÚJO, 2014a).

Suas relações estão devidamente instituídas com áreas específicas, qual seja aquela cuja informação também é objeto de estudo, como na Arquivologia, Biblioteconomia e Museologia (SMIT, 2000; ARAÚJO, 2014a). No entanto, é importante

\footnotetext{
${ }^{1}$ WINTER, Michael. Specialization, territoriality, and jurisdiction: librarianship and the political economy of knowledge. Library Trends, v. 45, n. 2, Fall, 1996.
} 
discorrer que, ao analisar o desenvolvimento desses campos do saber, percebe-se que eles relacionam-se com maior intensidade à Ciência da Informação, graças ao aspecto cultural atribuído às unidades de informação, sejam elas arquivos, bibliotecas ou museus. Por fim, ao mesmo tempo em que a Biblioteconomia converge à Ciência da Informação, ela também se diferencia em alguns aspectos, desenvolvendo possibilidades múltiplas de distanciamento e aproximação simultâneos (ARAÚJO, 2014a).

É nesse contexto que se evidencia os limites de aproximação ou distanciamento entre Biblioteconomia e a Ciência da Informação. Para Oliveira (2005), a Ciência da Informação possui como tarefa principal aprofundar-se nas questões de uso da informação na geração de conhecimento para o usuário, o que requer estudos voltados para questões cognitivas, psicológicas e sociais, que ultrapassam as fronteiras delimitadas pelo campo da Biblioteconomia.

Assim, a Ciência da Informação condiciona às unidades de informação, a serem vistas como:

[...] espaços documentais e informacionais e agentes catalisadores da cultura das comunicações nas quais estão inseridas, precisam ser efetivamente reconhecidas e utilizadas como instrumentos para a construção e a apropriação coletiva do conhecimento [...] (SILVA, 2004, p. 103).

É práxis entender o motivo do gerenciamento da informação, tendo em vista facilitar a recuperação e o uso das informações. Esse uso, obviamente requer a presença de um usuário, o que determina novas concepções acerca das últimas etapas do ciclo informacional. Assim, na modernidade, os fazeres propostos pela Ciência da Informação, além de preocuparem-se com as técnicas de gerenciamento, também estão

[...] muito ligados a atitudes e comportamentos éticos, tanto em relação ao usuário, quanto em relação ao próprio fazer informacional, ou seja, desde a prospecção e filtragem de dados e 
informações, até a disseminação e transferência desses mesmos dados e informações ao público interessado (VALENTIM, 2004, p. 55).

Nesse contexto, a Ciência da Informação se sustenta no tripé: tecnologias da informação, novas atribuições aferidas à Documentação e ao aparecimento de inúmeros estudos sobre os fatores que perpassam o processo de busca e recuperação da informação, processo esse que perfaz os estágios de disseminação e uso da informação, no âmbito dos fluxos informacionais.

De acordo com Ortega (2004), a evolução das técnicas biblioteconômicas e o surgimento de novas práticas desencadearam novos problemas, no decurso do século XIX, os quais constituíram a gênese do desenvolvimento da Ciência da Informação em meados do século seguinte. Em grande parte, uma evolução preliminar dessas práticas diz respeito à adoção de procedimentos voltados para o conteúdo dos documentos armazenados nas unidades de informação, ocasionado, dessa forma, o aparecimento da Documentação.

\section{O AVANÇO DA DOCUMENTAÇÃO}

O aparecimento da Ciência da Informação deve-se, em alguns aspectos, ao desenvolvimento da Documentação, a qual constitui uma disciplina científica, surgida paralelamente ao crescimento das práticas bibliotecárias realizadas nas unidades de informação no contexto das revoluções científicas ocorridas no iniciar da Idade Moderna (ARAÚJO, 2014a).

Dentre essas diversas disciplinas, tais como a Documentação e a Bibliografia, a Biblioteconomia se destaca como campo de conhecimento mais abrangente, uma vez que as práticas bibliotecárias datam de tempos milenares. Portanto, tais disciplinas surgem a partir da necessidade de novos produtos e serviços a serem desenvolvidos nas unidades de informação, haja vista, custodiar a produção intelectual produzida pelas sociedades 
(ARAÚJO, 2013).

As correntes teóricas que sustentaram a Biblioteconomia têm seu auge a partir da consolidação dessa área como disciplina científica, fenômeno esse ocorrido no decorrer do século XIX. Araújo (2013, p. 44) discorre que o modelo vigente no final do século XIX, acabava por privilegiar "[...] um pensamento voltado essencialmente 'para dentro': para os documentos e coleções guardadas nas bibliotecas; para as rotinas e dinâmicas das bibliotecas; e para as regras de catalogação e classificação das coleções [...]”. Essa tendência caracterizou o pensamento funcionalista da Biblioteconomia, sendo ampliado ao longo do século seguinte, sobretudo com o avanço dos suportes informacionais e com as novas concepções originadas com a valorização da biblioteca pública.

Assim, a diversificação dos suportes acarretou novas técnicas para organização dos documentos, principalmente quanto à elaboração de catálogos, sistematizados por meio dos conteúdos abordados nos documentos, trabalho esse de responsabilidade da Documentação (ORTEGA, 2004).

Ora, percebe-se que a Documentação manifesta-se paralelamente ao momento em que a Biblioteconomia consolida-se como área científica. No entanto, é importante considerar que a gênese ou embrião da documentação, como também a evolução das práticas bibliotecárias estão relacionadas à tecnologia da imprensa. Portanto,

O livro impresso foi o primeiro produto intelectual uniformemente reproduzido que permitiu o aumento em larga escala da difusão do conhecimento para as massas, adquirindo assim uma vigência social jamais vista. Porém, o aumento da produção bibliográfica gerou a necessidade de novas ferramentas de organização e recuperação das coleções, que cresciam vertiginosamente. Além dos catálogos e inventários que se especializaram nessa época, destacou-se o desenvolvimento das bibliografias a partir do século XVI - a origem remonta à Idade Antiga, quando eram feitas de forma limitada, mas pouco diferente da atual (SIQUEIRA, 2010, p. 57). 
Dentre os grandes marcos históricos descritos por Araújo (2013), os quais evidenciaram novas reflexões acerca do aparecimento de novas disciplinas a fim de contribuir com o trabalho de organização e disseminação do conhecimento, destaca-se o Renascimento e a Revolução Francesa. No primeiro movimento, renasceu o interesse pela produção humana, pelas obras artísticas, filosóficas e científicas - tanto as da Antiguidade Greco-romana como aquelas que se desenvolviam no próprio momento. Já no segundo marcou-se a transição do Antigo Regime para a Modernidade, em que ocorreu uma profunda transformação em todas as dimensões da vida humana - inclusive nas bibliotecas, fato esse que despertou a necessidade de formação profissional especializada para desenvolver novos produtos e serviços, conforme as demandas sociais da época (ARAÚJO, 2013).

Posto isso, entende-se que as revoluções ocorridas no período do Modernismo foram as "molas propulsoras" que viabilizaram o cientificismo bibliotecário e dessa transformação à Biblioteconomia nascem novas ciências como a Documentação e, posteriormente, a Ciência da Informação.

Com efeito, a Documentação exerceu influências significativas na Biblioteconomia e Ciência da Informação, pois é através das técnicas propostas pela Documentação que as práticas tradicionais de organização de coleções são repensadas, originando, desse pensamento, novos questionamentos de como melhor organizar e disseminar informação para diferentes demandas e diferentes contextos e com suportes tecnológicos variados. Dessas reflexões, ampliam-se as práticas, por conseguinte, novos desafios surgem, o que requer contribuição de outras áreas do conhecimento, não cabendo apenas à Biblioteconomia discorrer sobre essas novas questões, fato esse que viabiliza o nascimento de uma nova ciência, a Ciência da Informação (ARAÚJO, 2013; ARAÚJO, 2014b).

De acordo com a pesquisa de Oliveira (2005), a Documentação é instituída oficialmente como campo do conhecimento a partir dos estudos de Paul Otlet e Henri Fontaine no final do século XIX, com a proposta de se construir um sistema de classificação que abarcasse todas as áreas do conhecimento. Essa tentativa não atingiu seu real objetivo, mas, por outro lado, contribuiu na formação do Sistema de Classificação 
Universal (CDU), muito utilizado na classificação de acervos bibliográficos (por assuntos).

Esses autores ampliam as características dos itens considerados como documentos. Qualquer objeto que está sujeito a tratamento temático e/ou descritivo pode constituir um documento. Desse modo, documento é o livro, a revista, o jornal, é a peça de arquivo, a estampa, a fotografia, a medalha, a música, é também atualmente o filme, o disco e toda a parte documental que prece ou sucede a emissão radiofônica. Ao lado dos textos e imagens há objetos documentais por si mesmos (OTLET, 1937).

Ademais, esse novo conceito de documento "[...] ampliou o campo de atuação dos profissionais da área ao ultrapassar os limites do espaço da biblioteca e agregar novas práticas de organização e novos serviços de informação [...]" (OLIVEIRA, 2005, p. 11). E é nesse contexto que a Ciência da Informação amplia suas demarcações que extrapolam as limitações e preocupações da Biblioteconomia.

Com o novo conceito de documento, a informação é tratada sob dois enfoques: o arquivístico e o bibliográfico. Analisando sob uma ótica mais arquivística, o documento, em geral, a partir dessa expansão se estende a

Todos os livros, papéis, mapas, fotografias ou outras espécies documentárias, independentemente de sua apresentação física ou características, expedidos ou recebidos por qualquer entidade pública ou privada no exercício de seus encargos legais ou em função das suas atividades e preservados ou depositados para preservação por aquela entidade ou por seus legítimos sucessores como prova de suas funções, sua política, decisões, métodos, operações ou outras atividades, ou em virtude do valor informativo dos dados neles contidos (SCHELLENBERG, 2006, p. 41).

Como se percebe, grande contribuição à Documentação foi proposta pela brilhante tentativa de Paul Otlet e Fontaine criarem um arquivo universal. Através de suas 
ideias foi-se criada a Federal Internacional de Documentação (FID), responsável pela gestão do Instituto Internacional de Bibliografia, do qual surge "[...] a ideia de bibliografia como registro, memória do conhecimento científico, desvinculadas dos organismos como arquivos e bibliotecas, e de acervos" (OLIVEIRA, 2005, p. 11).

Aqui, tem-se a confirmação de que toda e qualquer evolução das ciências que lidam com a informação foi propiciada, a priori, pelo crescimento desenfreado da produção intelectual gerada pelas sociedades. Portanto, o estabelecimento de novas práticas e metodologias de trabalho, assim como a criação de institutos de guarda e disseminação da informação está diretamente ligado ao desenvolvimento dos suportes que armazenam a informação.

Nesse âmago, segundo Siqueira (2010), no que se refere à necessidade do nascimento da Documentação, é no final do século XIX, com o aumento da produção bibliográfica, da pesquisa científica e o surgimento de novos suportes houve a necessidade do desenvolvimento de outras técnicas para organização e administração da informação, já que a Bibliografia não dava mais conta de tais necessidades.

É importante mencionar, outrossim, que essas revoluções ocasionadas aos suportes de informação irão repercutir em novos caminhos a serem trilhados, gerando novos interesses de pesquisa, sobretudo a partir de uma visão crítica atribuída a tais práticas (ARAÚJO, 2013). As questões que ganham destaque no final do século XX, segundo Araújo (2014a), desvinculam-se do suporte informacional, principalmente pela ampliação do conceito de informação, e surge a necessidade de estudar o comportamento e o uso da informação, o que ocasiona discussões acerca dos usuários da informação.

A preocupação com o uso da informação é despertada, principalmente, com o valor que a informação passou a ter no período pós-segunda guerra mundial. As rivalidades entre as nações na busca por poder e domínio, considerando os impactos gerados economicamente com a guerra fez crescer a necessidade de se ampliar os canais de disseminação e acesso à informação, nascendo, dessa forma, interesse em estudar não apenas o armazenamento da informação, mas também seu uso, a sua recuperação (ORTEGA, 2004).

O avanço da Documentação, portanto, é um dos fatores que interferiu na 
evolução da Biblioteconomia e nascimento da Ciência da Informação. No entanto, a partir do caos gerado com a segunda guerra mundial, a Recuperação da Informação ganha força, consolidando novas percepções paradigmáticas, relacionadas ao uso e usuário das informações (SIQUEIRA, 2010).

De acordo com a autora supracitada, em meio ao interesse pela pesquisa científica e tecnológica, origina-se a explosão informacional, por conseguinte, consolidase "[...] uma demanda para a emergência de um campo preocupado com a recuperação da informação, acesso e uso de novas tecnologias, já que a informação ganhou um valor estratégico para os governos [...]" (SIQUEIRA, 2010, p. 60, grifo nosso).

Assim, da Documentação à Recuperação da Informação, assiste-se um conjunto de transformações acirradas, as quais proporcionaram novos rumos e fazeres à Biblioteconomia, como também, viabilizou o nascimento de uma nova ciência, a Ciência da Informação, estando esses campos dos saberes em constante interação e complementação.

\section{AS QUESTÕES DA RECUPERAÇÃO DA INFORMAÇÃO}

As necessidades demandadas no contexto do pós-segunda guerra mundial adentraram-se a questões de como transformar a informação armazenada em larga escala nos acervos e estoques de informação em conhecimento, de modo a gerar valor para quem dela se apropria, logo, desencadeando a formulação de estratégias para a resolução de problemas.

É nesse contexto que os profissionais que tradicionalmente estavam envolvidos com as técnicas de organização, sejam bibliotecários quanto documentalistas, adquirem novas habilidades, no intuito de permitir um acesso efetivo às informações tratadas e disponibilizadas (ORTEGA, 2004).

Assim, nas últimas décadas, o surgimento de tecnologias avançadas tem propiciado a construção de sistemas informatizados, os quais são construídos de modo a facilitar o manuseio e entendimento do usuário, cujo objetivo dessa elaboração, seja 
reduzir as limitações de tempo e de espaço, ampliando as possibilidades de acesso à informação, portanto, garantindo, satisfação ao usuário que busca por diferentes demandas informacionais (ARAÚJO JÚNIOR, 2007).

Ademais, a recuperação da informação é uma disciplina voltada para as metodologias de disseminação da informação, estando fortemente atrelada aos serviços de dinamização das coleções existentes nos acervos de unidades de informação, evidenciando a prática da literatura indexada (LANCASTER; WARNER, 1993² apud CENDÓN, 2005).

A elaboração de técnicas necessárias à recuperação perpassa o contexto da construção de linguagens documentárias, as quais conferem estratégias para encontrar a informação armazenada em bancos de dados, estruturadas de forma a facilitar a localização do item quando solicitado pelo usuário, sendo que essas estruturas podem ser construídas de forma analógica ou digital, todavia, na atualidade, a maioria dos sistemas de recuperação da informação é gerado a partir de recursos computacionais, ou seja, são informatizados (CENDÓN, 2005).

A eficiência dos sistemas de recuperação da informação informatizados adquire vantagens inquestionáveis, pois, "[...] esses sistemas favorecem maior número de pontos de acesso, podendo-se, pesquisar por palavra chave, que aparecem em qualquer ponto do registro, inclusive no resumo e no texto completo quando esses estão disponíveis [...]" (CENDÓN, 2005, p. 62).

A evolução tecnológica proporciona que esses sistemas sejam cada vez mais aperfeiçoados, desencadeando melhorias nas práticas de buscar e recuperar a informação, tendo em vista, tornar a informação cada vez mais recuperável (ARAÙJO JUNIOR, 2007). Além dessa vantagem, qual seja, tornar a informação mais recuperável, paralelamente, tem-se a satisfação do usuário, que, segundo Saracevic (1996), constitui uma das preocupações primordiais da Ciência da Informação, ou seja, essa ciência extravasa preocupações técnicas, objetivando viabilizar um harmonioso equilíbrio entre o humano e as máquinas.

\footnotetext{
${ }^{2}$ LANCASTER, F. W.; WARNER, A. J. Information Retrieval Today. Information Resources Press, 1993.
} 
Como se observa, a Recuperação da Informação representou um marco, um avanço histórico na Ciência da Informação, principalmente, pelo fato do acúmulo de informações que surgiram no período pós-segunda guerra mundial. Todavia, alguns problemas se consolidaram, tais como: a) como descrever intelectualmente a informação? b) como especificar intelectualmente a busca?, e, por fim, c) que sistemas, técnicas ou máquinas devem ser empregados? (SARACEVIC, 1996).

Sobre essas questões atreladas à prática da Recuperação da Informação e a tentativa de ampliar as possibilidades de acesso ao conhecimento, tem-se aqui uma preocupação voltada ao usuário da informação. Essa preocupação, em linhas gerais, está relacionada à corrente pós-moderna da Biblioteconomia, ou seja, o pensamento crítico (ARAÚJO, 2013), que, em países democráticos, com o desenvolvimento das ideias liberais, desenvolve-se uma tendência de democratização do conhecimento na sociedade.

Assim, acredita-se que as primeiras manifestações da Ciência da Informação talvez estejam relacionadas ao pensamento crítico vivenciado pela Biblioteconomia, tendo como paradigma de sustentação, o usuário da informação. Na visão de Araújo (2013, p. 47, grifo nosso) quando menciona a corrente pós-moderna da Biblioteconomia, ou seja, o pensamento crítico, discute-se que:

A manifestação de uma perspectiva crítica na Biblioteconomia se deu de forma bastante vinculada aos processos de redemocratização após ditaduras militares, nos quais houve forte censura à circulação de livros. Assim, num primeiro momento, desenhou-se um conjunto de práticas voltadas para população excluídas ou marginalizadas (extensão bibliotecária, carros-biblioteca, serviços de caixa estante) que buscavam alargar o acesso físico aos livros por meio da proximidade espacial.

Araújo (2013) defende que essas foram as primeiras tentativas de democratização, sendo que o avanço tecnológico tem ampliado as possibilidades de 
aproximação da informação a seu usuário. O autor ainda apresenta que, em muitos casos, tais práticas passaram a ser descritas como de "ação cultural" ou de "animação cultural". Para além do conjunto de iniciativas práticas e linhas de atuação geradas no campo biblioteconômico, houve também uma importante contribuição epistemológica.

Voltando ao raciocínio de Saracevic (1996), no que se refere à recuperação da informação, é importante enfatizar que o trabalho determinado pela necessidade de recuperar informações suscitou questões e promoveu pesquisas exploratórias de fenômenos, processos e variáveis, bem como das causas, efeitos, comportamentos e manifestações relacionados. Com o passar dos tempos, as pesquisas nessa área se acentuaram, despertando o interessante por questões complexas e amplas a respeito da

[...] natureza da informação, a estrutura do conhecimento e seus registros (incluindo bibliometria), o uso e os usuários, levando a estudos do comportamento humano frente à informação; a interação homem-computador, com ênfase no lado humano da equação; relevância, utilidade, obsolescência e outros atributos do uso da informação juntamente com medidas e métodos de avaliação dos sistemas de recuperação da informação; economia, impacto e valor da informação, dentre outros (SARACEVIC, 1996, p. 45).

É evidente que, nesse contexto, o uso do computador e a evolução das tecnologias da informação consolidaram-se como sustentadoras e motivadoras do campo delimitado pela Ciência da Informação. Desse modo, “[...] os avanços da informática desde a década de 1960 transformaram e estimularam as atividades de armazenamento e recuperação da informação. Com a utilização do computador, a Ciência da Informação passou a enfrentar novos desafios [...]" (OLIVEIRA, 2005, p. 15).

O surgimento dos sistemas de Recuperação da Informação (SRI's) automatizados contribuiu em grande escala para o desenvolvimento de pesquisas na área. Esse interesse tende a crescer, uma vez que, vive-se na sociedade em redes, em que as 
sociedades se comunicam instantaneamente transmitindo informações em grandes volumes e alta rapidez (CASTELLS, 2003).

Segundo Cendón (2005), os SRI's automatizados favorecem grandes vantagens ao processo de busca e recuperação da informação, proporcionando ganhos ao usuário da informação. Isso porque os usuários identificam-se diversas peculiaridades que não estão contempladas nos modelos tradicionais (impressos). Na busca de um referencial mais satisfatório, percebe-se a possibilidade de desenvolver uma proposta alternativa a esses modelos.

Como se percebe, a disciplina Recuperação da Informação sustenta-se em meio a inúmeras questões que se apresentam como problemáticas, mas que, se resolvidas, tendem a desencadear grandes melhorias no acesso à informação. A sociedade produz informações em altíssimas proporções, sendo que o problema maior não é seu tratamento e armazenamento, mas sim, sua recuperação, seu acesso e seu uso. Eis aí, grandes preocupações da Ciência da Informação que vai além das preocupações da Biblioteconomia (OLIVEIRA, 2005).

Em suma, esses grandes desafios geram a necessidade do desenvolvimento continuado de pesquisas e experiências interdisciplinares, o que favorece o engajamento e reconhecimento dos profissionais da informação e bibliotecários, dentre outras áreas correlatas, no sentido de unirem esforços em prol da resolução dessas questões.

É preciso também destacar a necessidade de capacitação/preparação do usuário desses sistemas automatizados. Para Araújo e Dias (2005), é missão de todos os profissionais da informação colocarem-se a serviço da capacitação dos cidadãos para utilizar os instrumentos e serviços oferecidos pelas redes de comunicação eletrônica e potencializar as informações acessadas, ou seja, a capacidade de compreender as informações, tornando-as úteis e componentes de sua vida cotidiana.

Em suma, através do avanço da Documentação e da preocupação com a Recuperação da Informação, consolida-se o paradigma emergente, aquele que considera o usuário como principal elemento que sustenta as práticas em informação. Nesse âmago, percebe-se a interligação entre a Biblioteconomia e Ciência da Informação, suas semelhanças e diferenças, no entanto, devem-se considerar as concepções paradigmáticas 
que sustenta cada uma dessas áreas (ARAÚJO, 2014a).

Posto isso, concorda-se com Araújo (2013), quando afirma que a Biblioteconomia ampliou seu escopo de estudos e problematizações com o desenvolvimento de teorias e pesquisas no século $\mathrm{XX}$, tendo a interdisciplinaridade, a Documentação e a Recuperação da Informação exercido fortes influências, a qual contribuiu, paralelamente, para o desenvolvimento da Ciência da Informação.

\section{CONSIDERAÇÕES FINAIS}

Este estudo apresentou breves e preliminares discussões a respeito do relacionamento existente entre Biblioteconomia e Ciência da Informação e sua formação e desenvolvimento ao longo dos tempos.

Por meio da revisão teórica em coletâneas e artigos da área, é possível concluir que existem grandes semelhanças entre ambas as áreas, todavia, a Ciência da Informação possui uma abrangência superior, que extrapola os limites da Biblioteconomia, enfocando aspectos relacionados ao uso, busca e recuperação da informação. Essa marcante interdisciplinaridade e a falta de limitações no escopo de atuação dificultam a separação de ambas as áreas, o que permite inferir que elas são complementares.

Em suma, com as leituras e reflexões dos textos, infere-se que os fortes relacionamentos entre Ciência da Informação e Biblioteconomia e a falta de clareza e objetividade ao delimitar os limites entre cada área, favorece o crescimento dessas áreas nos próximos anos, consolidando o trabalho de pesquisas, trocas de vivências e experiências, na tentativa de resolver questões complexas oriundas da recuperação e do uso da informação na sociedade.

Com isso, fica evidenciado que os bibliotecários são privilegiados nesse contexto de interação entre as duas áreas, uma vez que adquirem novas oportunidades de trabalho, sustentando seus fazeres de forma interdisciplinar, não se limitando apenas às atribuições profissionais demandadas pela legislação, mas adquirindo novas habilidades e competências, sobretudo no que se refere às questões complexas demandadas pela 
Ciência da Informação.

Assim, novas práticas profissionais só tendem a crescer no futuro, reservando para os profissionais da informação, grande reconhecimento e necessidade de atuação no mercado de trabalho, determinando nos fazeres desses profissionais um futuro esperançoso. Grandes expectativas, anseios e desejos são esperados para o amanhã, tendo os profissionais da informação grande participação na resolução de problemas oriundos da explosão da informação.

Por fim, esses fatos constatam a permanência e contínuo crescimento da atuação do bibliotecário no mercado, tendo a Biblioteconomia e Ciência da Informação grande destaque, o que confere sua permanência nas sociedades humanas por longas e extensas gerações.

\title{
Library And Information Science And The Limits Of Interdisciplinarity: Promoting Business Practices
}

\begin{abstract}
Aims to discuss relational aspects of information science and librarianship, delineating the limits of performance and scope of each, in order to demonstrate the interdisciplinary and systemic character covered in both areas. Through literature review in Brazilian collections on the subject, we seek to determine evidence to support the expansion of the labor market for information professionals, emphasizing the contribution of new technologies and the information society in the marked development of these areas of knowledge. Concludes that the two areas are related and complementary, but each with its scope of scientific and professional practice, and the interdisciplinary trend favors the expansion of professional practices, establishing new research and professional skills, integrating a continuous cycle and strongly established.
\end{abstract}

Keywords: Information Science. Librarianship. Information Professional. New Technologies. Documentation. Interdisciplinarity. 


\section{REFERÊNCIAS}

ALMEIDA JÚNIOR, Oswaldo Francisco de. Profissional da informação: entre o espírito e a produção. In: VALENTIM, Marta Lígia (Org.). Profissionais da informação: formação, perfil e atuação profissional. São Paulo: Polis, 2000, p. 31-51.

ARAÚJO, Eliany Alvarenga; OLIVEIRA, Marlene de. A produção de conhecimento e a origem das bibliotecas. In: OLIVEIRA, Marlene de (Coord.). Ciência da Informação e Biblioteconomia: novos conteúdos e espaços de atuação. Belo Horizonte: UFMG, 2005. p. 29-42.

ARAÚJO, Eliany Alvarenga; DIAS, Guilherme Atayde. A atuação profissional do bibliotecário no contexto da Sociedade da Informação: os novos espaços de informação. In: OLIVEIRA, Marlene de. Ciência da Informação e Biblioteconomia: novos conteúdos e espaços de atuação. Belo Horizonte: UFMG, 2005. p. 111-122.

ARAÚJO, Carlos Alberto Ávila. Correntes teóricas da Biblioteconomia. São Paulo, Revista Brasileira de Biblioteconomia e Documentação, v. 9, n. 1, p. 40-57, jan./dez. 2013. Disponível em: <https://rbbd.febab.org.br/rbbd/article/view/247/250>. Acesso em: 7 nov. 2015.

Arquivologia, Biblioteconomia, Museologia e Ciência da Informação: o diálogo possível. Brasília, DF: Briquet de Lemos, 2014a.

. O que é a Ciência da Informação. Informação e Informação, Londrina, v. 19, n. $1, \quad$ p. 1-30, jan./abr. 2014b. Disponível em: <http://www.uel.br/revistas/uel/index.php/informacao/article/view/15958/14205>. Acesso em: 15 mar. 2016.

ARAÚJO JÚNIOR, Rogério Henrique de. Precisão no processo de busca e recuperação da informação. Brasília: Thesaurus, 2007.

ASIST. Sparting Synergies: bringing research and practice together: call for participation. 2005. Disponível em: <http://www.asis.org/am05call.htm>. Acesso em: 16 mar. 2016. 
BAPTISTA, Sofia Galvão. As oportunidades de trabalho existentes na internet na área de construção de páginas de unidade de informação. In: ; MUELLER, Suzana Pinheiro Machado (Org.). Profissional da informação: espaço de trabalho. Brasília: Thesaurus, 2004. p. 224-241.

; MUELLER, Suzana Pinheiro Machado (Org.). Profissional da informação: espaço de trabalho. Brasília: Thesaurus, 2004.

BORKO, Harold. Information science: what is it? American Documentation, v. 19, n. 1, p. 3-5, 1968.

CASTELLS, Manuel. A Sociedade em rede. 7. ed. São Paulo: Paz e Terra, 2003.

CENDÓN, Beatriz Valadares. Sistemas e redes de informação. In: OLIVEIRA, Marlene de (Coord.). Ciência da informação e biblioteconomia: novos conteúdos e espaços de atuação. Belo Horizonte: UFMG, 2005. p. 45-75.

CLASSIFICAÇÃO BRASILEIRA DE OCUPAÇÕES - CBO. 2003. Disponível em: <www.mtecbo.gov.br>. Acesso em: 14 fev. 2014.

GUIMARÃES, José Augusto Chaves. Moderno profissional da informação: elementos para sua formação no Brasil. Transinformação, Marília, v. 9, n. 1, p. 124-137, 1997.

LE COADIC, Yves-François. A ciência da informação. 2. ed. Brasília: Briquet de Lemos, 2004.

MUELLER, Suzana Pinheiro Machado. A pesquisa em Ciência da Informação no contexto das Ciências Humanas. DataGramaZero, São Paulo, v. 1, n. 6, dez. 2000.

NEVES, Dulce Amélia; CRUZ, Emília Barroso. Transacionando com os campos do saber. In: ENCONTRO NACIONAL DE PESQUISA EM CIÊNCIA DA INFORMAÇÃO, 12., 2000, Brasília. Anais... Brasília: IBICT, 2000.

OLIVEIRA, Marlene de. Origens e evolução da Ciência da Informação. In:

(Coord.). Ciência da Informação e Biblioteconomia: novos conteúdos e espaços de atuação. Belo Horizonte: UFMG, 2005. p. 9-28. 
ORTEGA, Cristina Dotta. Relações históricas entre Biblioteconomia, Documentação e Ciência da Informação. DataGramaZero, Rio de Janeiro, v. 5, n. 5, out. 2004. Disponível em: <http://www.brapci.ufpr.br/documento.php?dd0=0000002048\&dd1=05069>. Acesso em: 15 mar. 2016.

OTLET, Paul. Documentos e documentação. 1937. Disponível em: <http://www.conexaorio.co m/biti/otlet/>. Acesso em: 12 fev. 2014.

SILVA, José Fernando Modesto da. O impacto tecnológico no exercício profissional em Ciência da Informação. In: VALENTIM, Marta Lígia Pomim (Org.). Atuação profissional na área de informação. São Paulo: Polis, 2004. p. 83-96.

SARACEVIC, Tefko. Ciência da informação: origem, evolução e relações. Perspectivas em Ciência da Informação, Belo Horizonte, v. 1, n. 1, p. 41-62, jan./jun. 1996. Disponível em: <file:///C:/Users/Guest/Desktop/235-630-1-PB.pdf>. Acesso em: 17 mar. 2016.

SCHELLENBERG, Theodore R. Arquivos modernos: princípios e técnicas. 6.ed. Rio de Janeiro: Editora FGV, 2006.

SIQUEIRA, Jéssica Câmara. Biblioteconomia, documentação e ciência da informação: história, sociedade, tecnologia e pós-modernidade. Perspectivas em Ciência da Informação, v. 15, n. 3, p. 52-66, set./dez. 2010. Disponível em: <file:///C:/Users/Guest/Desktop/04.pdf>. Acesso em: 17 mar. 2016.

SMIT, Johanna W. O profissional da informação e sua relação com as áreas de Biblioteconomia/Documentação, Arquivologia e Museologia. In: VALENTIM, Marta Lígia. (Org.). Profissionais da informação: formação, perfil e atuação profissional. São Paulo: Polis, 2000, p. 119-134.

VALENTIM, Marta Lígia Pomim. O moderno profissional da informação: formação e perspectiva profissional. Encontros Bibli: Revista de Biblioteconomia e Ciência da Informação. Florianópolis, n. 9, p. 16-27, jun. 2000.

(Org.). O profissional da informação: formação, perfil e atuação profissional.

São Paulo: Polis, 2000. 
(Org.). Formação do profissional da informação. São Paulo: Polis, 2002.

(Org.). Atuação profissional na área de informação. São Paulo: Polis, 2004.

(Org.). Ética profissional na área de ciência da informação. In: (Org.).

Atuação profissional na área de informação. São Paulo: Polis, 2004. cap. 3, p. 55-69.

Informações do autore

Jorge Santa Anna

Universidade Federal Do Espírito Santo

E-mail: jorjao20@yahoo.com.br

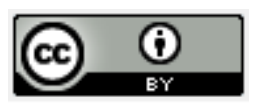

Recebido em 02.07.2014 e aceito para publicação em 25.07.2016 